The association between gait characteristics and ambulatory physical activity in older people: A cross-sectional and longitudinal observational study using Generation 100 data.

Thorlene Egerton ${ }^{1}$, Kade Paterson ${ }^{2}$, Jorunn L Helbostad ${ }^{1,3}$

${ }^{1}$ Department of Neuroscience, Faculty of Medicine, Norwegian University of Science and Technology, Trondheim, Norway.

${ }^{2}$ Centre for Health, Exercise and Sports Medicine, Department of Physiotherapy, School of Health Sciences, Faculty of Medicine Dentistry \& Health Sciences, The University of Melbourne, Melbourne, Australia.

${ }^{3}$ Department of Clinical Services, St. Olav University Hospital, Trondheim, Norway.

Running head: Gait and physical activity

Corresponding author details:

Thorlene Egerton, PhD

Department of Neuroscience,

Faculty of Medicine,

Norwegian University of Science and Technology,

Trondheim, Norway

Email: thor@sutmap.com

Ph: +61499382621 


\section{Acknowledgements and funding sources}

The authors wish to thank the study staff and participants of the Generation 100 study.

The work was supported by the K.G. Jebsen Center for Exercise in Medicine; the Health Authorities of Mid-Norway; Norwegian Women`s Health Association [TE]; and the Norwegian Extra Foundation for Health and Rehabilitation through EXTRA funds [TE]. 


\section{Abstract}

This study aimed to determine if temporal-spatial gait characteristics are associated with free-living ambulatory physical activity in relatively-healthy older people. 630 women and 593 men had valid data from gait tests and activity monitoring. Gait speed alone was associated with daily step count. Gait speed along with cadence, walk ratio, step length, step time, and swing time were associated with measures of higher intensity activity and overall activity. Those who walked slower were less active. After controlling for gait speed, shorter step length, shorter step time, shorter swing time and higher cadence were associated with less activity. This finding may be an indication of the functional consequences of a breakdown in the stride length-cadence relationship and/or compensations to increase stability. Asymmetry measures at preferred and fast walking speeds showed no association with physical activity levels. Gait speed was the only predictor of change in activity over the subsequent 12 months. 


\section{Introduction}

Physical inactivity is a leading cause of disease and disability and is the fourth highest risk factor for mortality globally (World Health Organization, 2011). Approximately one in three adults do not meet physical activity requirements, and this figure rises to nearly $50 \%$ in people aged over 60 years (Hallal et al., 2012). In older adults, low levels of physical activity are also a cardinal sign of frailty (Fried et al., 2001), which is a predisposition to future decline to dependency. Therefore, early identification of markers that predispose a person to lower levels of physical activity may help increase our understanding of what drives physical activity behaviours, and ultimately help increase activity participation.

A small number of studies have demonstrated associations between gait variables and physical activity levels in older adults. The findings suggest that gait impairment may be an indicator of lower activity levels in older adults with chronic disease. For instance, cross-sectional studies have shown that gait speed is moderately associated with daily step count in people with stroke (Michael, Allen, \& Macko, 2005; Mudge \& Stott, 2009), other neurological diseases (Busse, Wiles, \& van Deursen, 2006) and lower limb amputation (Lin, Winston, Mitchell, Girlinghouse, \& Crochet, 2014). Such evidence is currently lacking for the general older population.

Longitudinal research shows that gait characteristics may be predictive of future decline in healthrelated domains (den Ouden, Schuurmans, Arts, \& van der Schouw, 2011). In people aged over 70, slow walking speed and shorter stride length were shown to increase the risk of dependency and mortality over 36 months (Stanaway et al., 2011). Although gait speed is a useful gauge of overall performance, speed alone does not distinguish between different underlying pathologies (Lord, Galna, \& Rochester, 2013). Other gait variables have demonstrated discriminate and predictive 
ability for specific disorders including cognitive function (Verghese, Wang, Lipton, Holtzer, \& Xue, 2007) and falls (Verghese, Holtzer, Lipton, \& Wang, 2009). For example, gait asymmetry has been linked to fallers and people with Parkinson's disease (Aboutorabi, Arazpour, Bahramizadeh, Hutchins, \& Fadayevatan, 2015; den Ouden et al., 2011). However, evidence is lacking regarding the ability of gait characteristics, including gait asymmetry, to predict future decline in physical activity levels in older adults.

The aim of this study was to determine if temporal-spatial gait characteristics at baseline are associated with free-living ambulatory physical activity levels and whether any gait characteristics are predictive of future decline (over subsequent 12 months) in physical activity in community-living older people. We hypothesised that slower gait speed would be associated with lower levels of physical activity and would predict a decline in physical activity in the following year.

\section{Methods}

\section{Participants and procedures}

This cohort study used baseline and 12-month follow-up data from the Generation 100 study (Stensvold et al., 2015). All participants with both baseline gait and baseline and 12 month physical activity data were included in the analysis and thus determined the sample size. The Generation 100 study recruited 1567 participants aged 70-77 years from the municipality of Trondheim, Norway. Participants were randomised to one of two exercise protocols comprised of either high- or mediumintensity exercise training, or to a control group who received physical activity advice based on international recommendations. Participants were excluded if they had any illness or disability which would preclude participation in an exercise intervention or completion of the main study. Exclusions were mainly due to unstable cardiac disease, progressing cancer or dementia. Ethical approvals for the study and for use of data for observational analyses were granted by the Norwegian Ethical 
Review Board for Medical and Health Research (REK 2012/381B and 2013/787B), and all participants provided written informed consent.

\section{Gait characteristics}

The choice of gait variables for this study was based on previous studies that identified the key gait variables for representing the distinct domains of gait (Lord, Galna, Verghese, et al., 2013; Thingstad et al., 2015) and variables most commonly associated with other aging-related declines (Aboutorabi et al., 2015). Baseline gait data was collected using a 6.7m GAITRite ${ }^{\circledR}$ (CIR Systems Inc, Havertown, PA) walkway, with a $5.5 \mathrm{~m}$ active area, and sampling at $80 \mathrm{~Hz}$. The reliability and validity of the GAITRite ${ }^{\circledR}$ for collecting temporal-spatial gait data in older adults has been previously established (Bilney, Morris, \& Webster, 2003; Menz, Latt, Tiedemann, Mun San Kwan, \& Lord, 2004). Participants were asked to walk two passes each at both their preferred and fast walking speeds, defined as their usual and "as fast as you can safely walk" speeds. Fast walking speed was included because temporal-spatial gait parameters recorded during fast walking have been shown to predict multiple falls in older adults (Callisaya, Blizzard, McGinley, \& Srikanth, 2012). Participants commenced and terminated walking at least $1 \mathrm{~m}$ outside the mat (total walkway at least $8.7 \mathrm{~m}$ ) to permit acceleration and deceleration outside of the active area. The raw data was processed with the PKMAS ${ }^{\circledR}$ (V507C4I3, ProtoKinetics, Havertown, PA) software (Egerton, Thingstad, \& Helbostad, 2014) and exported to Microsoft Excel for calculation of asymmetry measures. Checks were carried out to identify processing errors by inspecting outliers, and if found, trials were reprocessed. The main variables of interest were average gait speed, cadence, step length and time, walk ratio, swing time and double support time as a percentage of the gait cycle (DS\%), and asymmetry. Walk ratio is a derived gait variable that has been shown to be a speed-independent, impairment-sensitive index of neuromotor control of gait (Rota, Perucca, Simone, \& Tesio, 2011). It was calculated by dividing step length by cadence. Thus if step length reduces for the same cadence, the walk ratio value will be lower. 
Asymmetry of step length, step time and swing time were calculated. To provide a measure of asymmetry, the following equation was used (Plotnik, Giladi, Balash, Peretz, \& Hausdorff, 2005; Yogev, Plotnik, Peretz, Giladi, \& Hausdorff, 2007):

$$
100 \times\left(\left|\ln \frac{L}{R}\right|\right) \quad \text { Equation } 1
$$

Where $\left|\ln \frac{L}{R}\right|$ is the log transformation of the left divided by right mean value, and $\mathrm{x} 100$ is a scaling factor. A value of 0.0 indicates perfect symmetry.

Walks were excluded if there were less than four complete steps within the active area. In the vast majority of cases, values for the two walks at each walking speed condition were averaged. If necessary, values from a single walk were used.

\section{Physical activity}

At the baseline and 12 month follow up assessments, participants were given an ActiGraph GT3X (ActiGraph, Pensacola, FL) accelerometer-based device to wear continuously on a belt around their waist, with the monitors on their right side, for seven consecutive days, apart from during waterbased activities. ActiGraph data were processed using ActiLife software (Version 6.11.5, ActiGraph, Pensacola, FL). The 'Troiano 2007' (Troiano, 2007) wear time validation method was used, whereby continuous periods of zero counts for 60 minutes or more, with a tolerance of up to two minutes of up to 100 CPM within the period, were defined as 'non-wear', and excluded from the analysis. Data was considered valid if there was a minimum of ten hours of wear time, on a minimum of four days. Data from eleven participants who wore the monitor did not meet these validity criteria and were excluded.

The ActiGraph GT3X records accelerations. The proprietary ActiLife software converts acceleration data into counts that increase linearly with the magnitude of the acceleration. Each sample of counts 
is summed over a user specified interval of time called an 'epoch'. For our study, the epoch was set to a 10 seconds interval which allows the highest resolution. The outcome variable was reported in minutes, that is, the number of vertical axis counts-min-1 (CPM). The activity counts reflect the intensity of bodily movement, thus the higher number of counts measured, the more active a person is (Hall, Howe, Rana, Martin, \& Morey, 2013). CPM is often used as an outcome variable due to its robustness as it is not influenced by any external criteria (i.e. intensity threshold) other than wear time validation. However, as there is a great deal of interest in moderate and higher intensity physical activity due to the health benefits it confers, studies have been carried out on Actigraph data to identify a cut point that can be used to reflect the intensity above which activity could be considered moderate or higher. The most commonly used cut point for moderate intensity activity from vertical axis Actigraph data is 1952 CPM (Freedson, Melanson, \& Sirard, 1998). That is, any minute during which more than 1952 counts were recorded was a minute of moderate or higher intensity activity

Activity outcomes derived from the raw data for the present study were:

1. Average CPM over all valid days of activity recording - Activity counts have been found to correlate well with energy expenditure when walking at different speeds and gradients (Herman Hansen et al., 2014). Thus average CPM provides an estimation of energy expenditure.

2. Minutes at $\geq 1952$ CPM per day (high intensity activity) - Activity at $\geq 1952$ CPM represents moderate and vigorous intensity activity among adults (Freedson et al., 1998). The term high intensity was used in our study instead of the traditional moderate-vigorous intensity descriptor because the cut point has not been validated as a threshold for moderate intensity activity in older people, who are the focus of this study.

3. Steps/day - Step counts can also be derived from vertical axis data using proprietary algorithms and many studies have published these data (Arias-Palencia et al., 2015; Barreira, Harrington, Schuna, Tudor-Locke, \& Katzmarzyk, 2015; Ferguson, Rowlands, Olds, \& Maher, 
2015). Validity of Actigraph step counts against direct observation has been demonstrated (Le Masurier, Lee, \& Tudor-Locke, 2004; Lee, Williams, Brown, \& Laurson, 2015). The number of steps was divided by the number of valid days for daily ambulatory activity.

The three measures used to characterize physical activity represent disparate domains of ambulatory physical activity: overall activity (CPM), amount of high intensity activity (minutes) and walking activity (steps/day). The change in physical activity $(\triangle \mathrm{PA})$ during 12 months was annualized as follows:

$$
\triangle P A=\frac{P A_{F U}-P A_{B L}}{N} \times 365 \quad \text { Equation } 2
$$

Where $P A_{F U}$ and $P A_{B L}$ are the activity parameters at follow up and baseline respectively, and $\mathrm{N}$ is the number of days between the baseline and follow-up measurements. Positive values indicate an increase in physical activity over the 12 month follow up period and negative values indicate reduced activity.

\section{Statistical analysis}

Data were described using mean and standard deviation (SD). Differences in each of the dependent (activity) outcome measures between sexes and between the intervention and control groups were checked using analyses of covariance (ANCOVA) with age and baseline activity included as covariates. These analyses revealed no between-group differences for any of the physical activity outcome measures at the time points used in this study therefore data from the three groups was pooled. However, the analyses revealed significant differences between women and men for all activity outcomes, and therefore the two sexes were analysed separately. To test for cross-sectional associations between the gait variables and the physical activity outcome measures, linear regression models were constructed, with baseline activity levels as the dependent variables and gait characteristics as the independent variables. Models were adjusted for age and gait speed. Finally, to investigate the ability of each of the gait variables to predict change in physical activity over 12 
months, linear regression analyses were conducted adjusting for age, gait speed and baseline activity levels, with $\triangle \mathrm{PA}$ as the dependent variables. All analyses were performed using SPSS, and a pvalue of $\leq 0.01$ was used to denote statistical significance due to the large numbers of analyses.

\section{Results}

The participants in the Generation 100 study are known to be more active (self-categorised), more highly educated and in better health than the population as a whole (Stensvold et al., 2015). Relevant descriptive details of the sample are provided in Table 1. The sample consisted of 1223 participants (630 women and 593 men) for the cross-sectional analysis (using baseline data only) and 833 participants (427 women and 406 men) for the longitudinal analysis (Figure 1).

The cross-sectional associations between the gait variables and physical activity are presented in Table 2. Among the gait variables in the preferred walking speed condition, gait speed alone was associated with all the activity outcome measures. The B values (unstandardised regression coefficient) can be used to derive clinical meaning from the regression analysis results. The B value for women for minutes of higher intensity activity was 0.25 . That means that for every $1 \mathrm{~cm} / \mathrm{sec}$ of difference in gait speed, a difference of 0.25 minutes of high intensity activity can be predicted. Thus for a $20 \mathrm{~cm} / \mathrm{sec}$ slower gait speed, we can predict 5 minutes $(20 \times 0.25)$ less high intensity activity is performed per day. For men a $20 \mathrm{~cm} / \mathrm{s}$ slower gait speed would be associated with 3.4 minutes less activity. Similarly, walking $20 \mathrm{~cm} / \mathrm{sec}$ slower is associated with 18 CPM and 20 CPM less for women and men respectively, which equates to around $9 \%$ of the average CPM. Finally $20 \mathrm{~cm} / \mathrm{sec}$ slower gait speed is associated with 578 and 424 fewer steps/day for women and men respectively. Cadence, walk ratio, step length, step time, and swing time were associated with high intensity activity time and average CPM but not steps/day. $\beta$ values (standardised regression coefficient) indicate how much of the association is explained, such that the higher the $\beta$ value, the stronger the association. 
Step length had the strongest association with high intensity activity time with $\beta$-values of 0.34 and 0.32 for women and men respectively. As expected, the association was positive with longer steps related to more activity. Cadence was negatively associated with the physical activity outcomes, suggesting that after controlling for gait speed, those with higher cadence had reduced activity. This finding is also reflected in the walk ratio which was positively associated with physical activity. Lower walk ratio values indicate higher cadence relative to step length. DS\% and all asymmetry variables had no association with physical activity at preferred walking speed. The strengths of the associations ( $\beta$ values) were largely similar for women and men although there was a tendency for the associations to be strongest in women for high intensity time and steps/day, and highest in men for average CPM.

The findings were generally very similar for fast speed condition gait variables although overall the strengths of the associations were smaller than for the preferred speed condition. The only notable exception was for stance time asymmetry which was negatively associated with both high intensity activity time and steps/day for women, and step length asymmetry which was negatively associated with high intensity activity for men. These measures were only associated with activity in the fast speed condition.

The longitudinal analysis showed that gait speed during both the preferred and fast walking speed conditions was positively associated with change over one year in all activity outcomes. That is, slower gait speed at baseline predicted increased likelihood of decline in physical activity. Specifically, our longitudinal results show that for women, a $20 \mathrm{~cm} / \mathrm{sec}$ slower gait speed predicts a 3.2 minutes per day greater loss in high intensity activity over the subsequent 12 months. Similarly, the $20 \mathrm{~cm} / \mathrm{sec}$ slower gait speed at baseline predicts a loss of 272 steps/day and 11 CPM one year later. For men, the decrease after one year is predicted to be 2.8 minutes per day of high intensity 
activity, 386 steps/day and 13 average CPM more for every $20 \mathrm{~cm} / \mathrm{sec}$ slower gait speed at baseline. In addition to the associations between gait speed and all activity outcomes, greater DS\% was associated with a negative change in activity outcomes for steps/day for women at both preferred and fast speed conditions and for average CPM for women at preferred speed. No other variables, including any of the asymmetry measures, had a statistically significant association with change in activity.

\section{Discussion}

This study explored the relationship between clinically-relevant gait characteristics that represent a range of underlying domains of gait, and objectively-measured free-living physical activity of older women and men. The findings showed that gait speed, step length, cadence, walk ratio, step time and swing time were associated with the baseline physical activity levels of higher intensity activity time (minutes above 1952 CPM) and overall daily energy expending activity (average CPM). Gait asymmetry at preferred speed was not associated with activity, and the few statistically significant associations found in the fast speed condition are probably not clinically meaningful. From the temporal-spatial gait variables we included, only walking speed was found to consistently predict future decline in physical activity over the subsequent 12 months, although DS\% was related to decline in some activity outcomes for women. There were few differences between women and men, and gait variables from fast speed walks were not more strongly associated with activity than preferred speed variables for the cross-sectional or longitudinal analyses. These findings suggest that although a number of temporal-spatial gait characteristics are associated with measures of physical activity, gait speed provides the best predictor of future change in community ambulatory physical activity. 
People who walked slower not only had lower levels of daily activity but were more likely to have a decline in activity levels over the next year. The associations, although statistically significant, may be small in the context of clinical significance. It is not known how many more minutes of higher intensity activity or steps/day are needed to achieve an important health benefit or prevent decline in health or function. A recent dose response study has shown that 2500 steps/day difference can discriminate between older adults' physical function levels (Dondzila et al., 2015). Others have suggested that every minute of higher intensity activity is important (Swain \& Franklin, 2006). It should be emphasised that this association between gait speed and future activity levels does not imply that walking slower causes decline in activity. Gait speed is a composite measure of gait function and was the only gait characteristic among those included in our study associated with change in activity levels for both women and men. Our results therefore do not support the notion that worse quality of gait, such as higher gait asymmetry, somehow causes one to decline in ambulatory activity in relatively healthy older people. The reverse causal pathway - that activity supports maintenance of gait performance - warrants testing in future research.

We found that among the women only, the time spent in double support was associated with reductions in some physical activity outcomes in the following 12 months. Greater double support time in older adults has been reported previously (Aboutorabi et al., 2015), however this is the first study to show that it may be associated with future declines in community ambulation. Increased double support time is suggested to be a compensatory mechanism to increase stability and reduce the risk of falls during walking (Aboutorabi et al., 2015), and as such, our finding may suggest that DS\% is a marker of instability which signals future activity avoidance. Given women are consistently reported to fall more often than men (Stevens \& Sogolow, 2005), our finding that an association between DS\% and physical activity decline is only apparent in women may be related to this sex difference in fall rate. Once again however, caution should be applied regarding assumptions of causality in this relationship. Future studies should consider examining the temporal sequence of 
these changes, along with exploring factors that explain or mediate the association including other balance measures and fall history.

The direction of the significant associations for gait speed and step length suggests older people with better gait performance have higher levels of physical activity. However faster cadence, smaller walk ratio, shorter step time and shorter swing time were associated with lower levels of physical activity after controlling for walking speed. This could be due to two reasons. Firstly, faster cadence, smaller walk ratio, shorter step time and shorter swing time relative to gait speed may reflect a compensation to increase stability during walking. The need to walk with a more cautious gait may also lead to lower overall activity counts and fewer minutes in higher intensity activities. Secondly, our findings may reflect subclinical changes in ageing- or disease-related changes in central control of gait. Gait in unconstrained environments is largely automatic and changes in speed are primarily achieved through a strong relationship between changes in stride length and cadence (Egerton, Danoudis, Huxham, \& lansek, 2011). Patients with degenerative neurological diseases such as Parkinson's disease and dementia demonstrate a disruption in the general linear relationship between these gait parameters (Egerton, Williams, \& lansek, 2012). As such, our finding that people with higher cadence relative to their speed had lower levels of physical activity may be the functional consequence of a breakdown in the stride length-cadence relationship.

There were several limitations that may have influenced our findings. Firstly, there are many gait variables that can be derived from data collected on an electronic walkway and it is possible that we missed an important association between a gait variable and physical activity. However, most gait variables are related to each other and the choice of variables was based on previous research identifying clinically important variables and those that have been shown through mathematical techniques to represent all the distinct domains of gait (Lord, Galna, Verghese, et al., 2013; Thingstad 
et al., 2015). Specifically, Lord et al showed that the gait of healthy older adults consists of five domains (pace, rhythm, postural control, variability and asymmetry) (Lord, Galna, Verghese, et al., 2013) and most of these domains were represented by at least one outcome variable in our study. Gait variability is often calculated from electronic walkway footfall data, however many of our trails consisted of 6 or fewer steps and studies have suggested at least 30 steps are required for valid calculation of variability (Galna, Lord, \& Rochester, 2013). Thus a calculation of variability from our data would have had questionable validity and reliability. Gait variability measures are predictive of future falling (Hausdorff, Rios, \& Edelberg, 2001; Maki, 1997), future mobility disability (Brach, Studenski, Perera, VanSwearingen, \& Newman, 2007) and frailty (Montero-Odasso et al., 2011), and therefore testing the relationship between gait variability and physical activity is recommended for future research.

Of note, the participants in this study all met the inclusion/exclusion criteria for a study with an exercise intervention, and volunteered for a study with an exercise component. They were relatively healthy, more highly education and had higher self-reported activity levels than the population as a whole, and this affects the generalisability of the findings to less healthy older people. Finally, although activity outcomes derived from accelerometer-based devices provide objective data that has been shown to be reliable and valid, they are not able to capture all domains of physical activity and important features of daily activity may have been missed. Regardless, the associations found in this study, although small in magnitude, are still notable given that there are numerous potential correlates with physical activity (Bauman, Sallis, Dzewaltowski, \& Owen, 2002).

\section{Conclusion}

Reduced gait speed, walk ratio, step length, step time and swing time, and increased cadence, were all associated with lower activity levels. Furthermore, reduced walking speed, and to a lesser extent 
increased double support time, were found to predict reductions in community-based ambulatory physical activity in the subsequent 12 months. Maintenance of physical activity levels in older people is an important goal of public health and rehabilitation services. Studies such as this can help identify factors that can be used to screen for people at risk of future decline, or identify possible interventions with the potential to help older people remain sufficiently physically active. Our study findings suggest that slow gait speed, which can be easily identified in a clinical setting, may be a red flag for future activity declines. Furthermore, further investigation is warranted to determine whether improvements in overall gait performance and postural stability can help older people achieve higher levels of activity. However further exploration of the relationship between gait and future decline in physical activity, including possible mediators and mechanisms responsible for the associations found in this study, is needed first.

\section{Competing interests}

The authors declare that they have no competing interests

\section{References}

Aboutorabi, A., Arazpour, M., Bahramizadeh, M., Hutchins, S. W., \& Fadayevatan, R. (2015). The effect of aging on gait parameters in able-bodied older subjects: a literature review. Aging Clin Exp Res. doi: 10.1007/s40520-015-0420-6

Arias-Palencia, N. M., Solera-Martinez, M., Gracia-Marco, L., Silva, P., Martinez-Vizcaino, V., CaneteGarcia-Prieto, J., \& Sanchez-Lopez, M. (2015). Levels and Patterns of Objectively Assessed Physical Activity and Compliance with Different Public Health Guidelines in University Students. PLoS One, 10(11), e0141977. doi: 10.1371/journal.pone.0141977 
Barreira, T. V., Harrington, D. M., Schuna, J. M., Jr., Tudor-Locke, C., \& Katzmarzyk, P. T. (2015). Pattern changes in step count accumulation and peak cadence due to a physical activity intervention. J Sci Med Sport. doi: 10.1016/j.jsams.2015.01.008

Bauman, A. E., Sallis, J. F., Dzewaltowski, D. A., \& Owen, N. (2002). Toward a better understanding of the influences on physical activity: the role of determinants, correlates, causal variables, mediators, moderators, and confounders. Am J Prev Med, 23(2 Suppl), 5-14.

Bilney, B., Morris, M., \& Webster, K. (2003). Concurrent related validity of the GAITRite walkway system for quantification of the spatial and temporal parameters of gait. Gait Posture, 17(1), 68-74.

Brach, J. S., Studenski, S. A., Perera, S., VanSwearingen, J. M., \& Newman, A. B. (2007). Gait variability and the risk of incident mobility disability in community-dwelling older adults. J Gerontol A Biol Sci Med Sci, 62(9), 983-988.

Busse, M. E., Wiles, C. M., \& van Deursen, R. W. (2006). Community walking activity in neurological disorders with leg weakness. J Neurol Neurosurg Psychiatry, 77(3), 359-362. doi:

10.1136/jnnp.2005.074294

Callisaya, M. L., Blizzard, L., McGinley, J. L., \& Srikanth, V. K. (2012). Risk of falls in older people during fast-walking--the TASCOG study. Gait Posture, 36(3), 510-515. doi: 10.1016/j.gaitpost.2012.05.003

den Ouden, M. E., Schuurmans, M. J., Arts, I. E., \& van der Schouw, Y. T. (2011). Physical performance characteristics related to disability in older persons: a systematic review. Maturitas, 69(3), 208-219. doi: 10.1016/j.maturitas.2011.04.008

Dondzila, C. J., Gennuso, K. P., Swartz, A. M., Tarima, S., Lenz, E. K., Stein, S. S., . . Strath, S. J. (2015). Dose-response walking activity and physical function in older adults. J Aging Phys Act, 23(2), 194-199. doi: 10.1123/japa.203-0083 
Egerton, T., Danoudis, M., Huxham, F., \& lansek, R. (2011). Central gait control mechanisms and the stride length - cadence relationship. Gait Posture, 34(2), 178-182. doi: 10.1016/j.gaitpost.2011.04.006

Egerton, T., Thingstad, P., \& Helbostad, J. L. (2014). Comparison of programs for determining temporal-spatial gait variables from instrumented walkway data: PKmas versus GAITRite. BMC Res Notes, 7, 542. doi: 10.1186/1756-0500-7-542

Egerton, T., Williams, D. R., \& lansek, R. (2012). Comparison of gait in progressive supranuclear palsy, Parkinson's disease and healthy older adults. BMC Neurol, 12, 116. doi: 10.1186/1471-2377$12-116$

Ferguson, T., Rowlands, A. V., Olds, T., \& Maher, C. (2015). The validity of consumer-level, activity monitors in healthy adults worn in free-living conditions: a cross-sectional study. Int J Behav Nutr Phys Act, 12, 42. doi: 10.1186/s12966-015-0201-9

Freedson, P. S., Melanson, E., \& Sirard, J. (1998). Calibration of the Computer Science and Applications, Inc. accelerometer. Med Sci Sports Exerc, 30(5), 777-781.

Fried, L. P., Tangen, C. M., Walston, J., Newman, A. B., Hirsch, C., Gottdiener, J., . . Cardiovascular Health Study Collaborative Research, G. (2001). Frailty in older adults: evidence for a phenotype. J Gerontol A Biol Sci Med Sci, 56(3), M146-156.

Galna, B., Lord, S., \& Rochester, L. (2013). Is gait variability reliable in older adults and Parkinson's disease? Towards an optimal testing protocol. Gait Posture, 37(4), 580-585. doi: 10.1016/j.gaitpost.2012.09.025

Hall, K. S., Howe, C. A., Rana, S. R., Martin, C. L., \& Morey, M. C. (2013). METs and accelerometry of walking in older adults: standard versus measured energy cost. Med Sci Sports Exerc, 45(3), 574-582. doi: 10.1249/MSS.0b013e318276c73c

Hallal, P. C., Andersen, L. B., Bull, F. C., Guthold, R., Haskell, W., Ekelund, U., \& Lancet Physical Activity Series Working, G. (2012). Global physical activity levels: surveillance progress, pitfalls, and prospects. Lancet, 380(9838), 247-257. doi: 10.1016/S0140-6736(12)60646-1 
Hausdorff, J. M., Rios, D. A., \& Edelberg, H. K. (2001). Gait variability and fall risk in community-living older adults: a 1-year prospective study. Arch Phys Med Rehabil, 82(8), 1050-1056. doi: 10.1053/apmr.2001.24893

Herman Hansen, B., Børtnes, I., Hildebrand, M., Holme, I., Kolle, E., \& Anderssen, S. A. (2014). Validity of the ActiGraph GT1M during walking and cycling. J Sports Sci, 32(6), 510-516. doi: $10.1080 / 02640414.2013 .844347$

Le Masurier, G. C., Lee, S. M., \& Tudor-Locke, C. (2004). Motion sensor accuracy under controlled and free-living conditions. Med Sci Sports Exerc, 36(5), 905-910.

Lee, J. A., Williams, S. M., Brown, D. D., \& Laurson, K. R. (2015). Concurrent validation of the Actigraph gt3x+, Polar Active accelerometer, Omron HJ-720 and Yamax Digiwalker SW-701 pedometer step counts in lab-based and free-living settings. J Sports Sci, 33(10), 991-1000. doi: $10.1080 / 02640414.2014 .981848$

Lin, S. J., Winston, K. D., Mitchell, J., Girlinghouse, J., \& Crochet, K. (2014). Physical activity, functional capacity, and step variability during walking in people with lower-limb amputation. Gait Posture, 40(1), 140-144. doi: 10.1016/j.gaitpost.2014.03.012

Lord, S., Galna, B., \& Rochester, L. (2013). Moving forward on gait measurement: toward a more refined approach. Mov Disord, 28(11), 1534-1543. doi: 10.1002/mds.25545

Lord, S., Galna, B., Verghese, J., Coleman, S., Burn, D., \& Rochester, L. (2013). Independent domains of gait in older adults and associated motor and nonmotor attributes: validation of a factor analysis approach. J Gerontol A Biol Sci Med Sci, 68(7), 820-827. doi: 10.1093/gerona/gls255

Maki, B. E. (1997). Gait changes in older adults: predictors of falls or indicators of fear. J Am Geriatr Soc, 45(3), 313-320.

Menz, H. B., Latt, M. D., Tiedemann, A., Mun San Kwan, M., \& Lord, S. R. (2004). Reliability of the GAITRite walkway system for the quantification of temporo-spatial parameters of gait in young and older people. Gait Posture, 20(1), 20-25. doi: 10.1016/S0966-6362(03)00068-7 
Michael, K. M., Allen, J. K., \& Macko, R. F. (2005). Reduced ambulatory activity after stroke: the role of balance, gait, and cardiovascular fitness. Arch Phys Med Rehabil, 86(8), 1552-1556. doi: 10.1016/j.apmr.2004.12.026

Montero-Odasso, M., Muir, S. W., Hall, M., Doherty, T. J., Kloseck, M., Beauchet, O., \& Speechley, M. (2011). Gait variability is associated with frailty in community-dwelling older adults. J Gerontol A Biol Sci Med Sci, 66(5), 568-576. doi: 10.1093/gerona/gIr007

Mudge, S., \& Stott, N. S. (2009). Timed walking tests correlate with daily step activity in persons with stroke. Arch Phys Med Rehabil, 90(2), 296-301. doi: 10.1016/j.apmr.2008.07.025

Plotnik, M., Giladi, N., Balash, Y., Peretz, C., \& Hausdorff, J. M. (2005). Is freezing of gait in Parkinson's disease related to asymmetric motor function? Ann Neurol, 57(5), 656-663. doi: 10.1002/ana.20452

Rota, V., Perucca, L., Simone, A., \& Tesio, L. (2011). Walk ratio (step length/cadence) as a summary index of neuromotor control of gait: application to multiple sclerosis. Int J Rehabil Res, 34(3), 265-269. doi: 10.1097/MRR.0b013e328347be02

Stanaway, F. F., Gnjidic, D., Blyth, F. M., Le Couteur, D. G., Naganathan, V., Waite, L., . . Cumming, R. G. (2011). How fast does the Grim Reaper walk? Receiver operating characteristics curve analysis in healthy men aged 70 and over. BMJ, 343. doi: 10.1136/bmj.d7679

Stensvold, D., Viken, H., Rognmo, O., Skogvoll, E., Steinshamn, S., Vatten, L. J., . . Wisloff, U. (2015). A randomised controlled study of the long-term effects of exercise training on mortality in elderly people: study protocol for the Generation 100 study. BMJ Open, 5(2), e007519. doi: 10.1136/bmjopen-2014-007519

Stevens, J. A., \& Sogolow, E. D. (2005). Gender differences for non-fatal unintentional fall related injuries among older adults. Inj Prev, 11(2), 115-119. doi: 10.1136/ip.2004.005835

Swain, D. P., \& Franklin, B. A. (2006). Comparison of cardioprotective benefits of vigorous versus moderate intensity aerobic exercise. Am J Cardiol, 97(1), 141-147. doi:

10.1016/j.amjcard.2005.07.130 
Thingstad, P., Egerton, T., Ihlen, E. F., Taraldsen, K., Moe-Nilssen, R., \& Helbostad, J. L. (2015). Identification of gait domains and key gait variables following hip fracture. BMC Geriatr, 15, 150. doi: $10.1186 / s 12877-015-0147-4$

Troiano, R. P. (2007). Large-scale applications of accelerometers: new frontiers and new questions. Med Sci Sports Exerc, 39(9), 1501. doi: 10.1097/mss.0b013e318150d42e

Verghese, J., Holtzer, R., Lipton, R. B., \& Wang, C. (2009). Quantitative gait markers and incident fall risk in older adults. J Gerontol A Biol Sci Med Sci, 64(8), 896-901. doi: 10.1093/gerona/glp033

Verghese, J., Wang, C., Lipton, R. B., Holtzer, R., \& Xue, X. (2007). Quantitative gait dysfunction and risk of cognitive decline and dementia. J Neurol Neurosurg Psychiatry, 78(9), 929-935. doi: 10.1136/jnnp.2006.106914

World Health Organization. (2011). Global recommendations on physical activity for health. Geneva: WHO.

Yogev, G., Plotnik, M., Peretz, C., Giladi, N., \& Hausdorff, J. M. (2007). Gait asymmetry in patients with Parkinson's disease and elderly fallers: when does the bilateral coordination of gait require attention? Exp Brain Res, 177(3), 336-346. doi: 10.1007/s00221-006-0676-3 
Table 1. Sample characteristics reported as mean (standard deviation).

\begin{tabular}{lcc}
\hline Cross-sectional analysis & Women $(\mathrm{n}=630)$ & Men $(\mathrm{n}=593)$ \\
\hline Age (years) & $73.5(1.9)$ & $73.3(1.9)$ \\
Preferred gait speed (cm/s) & $130.3(19.5)$ & $133.1(20.1)$ \\
Minutes of high intensity activity* per day & $34.9(19.7)$ & $38.5(22.0)$ \\
Average CPM & $210(78)$ & $214(94)$ \\
Steps/day & $6470(2245)$ & $6438(2508)$ \\
\hline Longitudinal analysis & Women (n=427) & Men (n=406) \\
\hline Age (years) & $73.4(1.9)$ & $73.1(1.9)$ \\
Preferred gait speed (cm/s) & $132.4(19.3)$ & $134.9(19.8)$ \\
Annualised difference in high intensity activity* per day & $-2.3(16.0)$ & $0.4(16.8)$ \\
Annualised difference in steps/day & $-209(1709)$ & $-84(1847)$ \\
Annualised difference in average CPM & $-18(60)$ & $-6(70)$ \\
\hline
\end{tabular}

* Defined as minutes with $>1952$ counts. CPM $=$ counts per minute. 
Table 2. Cross-sectional analyses of the association between gait variables and physical activity measures. All analyses were adjusted for age and gait speed (preferred or fast as appropriate).

\begin{tabular}{|c|c|c|c|c|c|c|}
\hline & \multicolumn{2}{|c|}{ Minutes of high intensity activity per day } & \multicolumn{2}{|c|}{ Average CPM } & \multicolumn{2}{|c|}{ Steps/day } \\
\hline & Women & Men & Women & Men & Women & Men \\
\hline & $\beta(\mathrm{B}: 95 \% \mathrm{Cl})$ & $\beta(\mathrm{B}: 95 \% \mathrm{Cl})$ & $\beta(B: 95 \% \mathrm{Cl})$ & $\beta(\mathrm{B}: 95 \% \mathrm{Cl})$ & $\beta(\mathrm{B}: 95 \% \mathrm{Cl})$ & $\beta(\mathrm{B}: 95 \% \mathrm{Cl})$ \\
\hline \multicolumn{7}{|c|}{ Preferred walking speed condition } \\
\hline $\begin{array}{l}\text { Preferred speed } \\
(\mathrm{cm} / \mathrm{s})\end{array}$ & $0.25(0.25: 0.17,0.32)^{*}$ & $0.16(0.17: 0.08,0.26)^{*}$ & $0.23(0.91: 0.61,1.22)^{*}$ & $0.21(0.98: 0.61,1.35)^{*}$ & $0.25(28.9: 19.6,38.1)^{*}$ & $0.17(21.2: 10.9,31.5)^{*}$ \\
\hline $\begin{array}{l}\text { Walk ratio } \\
\text { (cm/steps/min) }\end{array}$ & $0.17(58.5: 33.2,83.8)^{*}$ & $0.15(47.5: 20.6,74.5)^{*}$ & 0.14 (179.3: 78.0,280.6)* & $0.19(250.5: 137.1,363.8)^{*}$ & $0.07(2573:-464,5611)$ & $0.06(2327:-871,5526)$ \\
\hline Step length (cm) & $0.34(1.0: 0.6,1.5)^{*}$ & $0.32(0.9: 0.4,1.4)^{*}$ & $0.26(3.2: 1.4,5.0)^{*}$ & $0.39(4.6: 2.5,6.7)^{*}$ & 0.13 (44.7: $-8.1,97.5)$ & $0.13(42.6:-16.6,101.9)$ \\
\hline Step time (s) & $0.27(111.9: 57.2,166.6)^{*}$ & $0.21(102.3: 39.3,165.3)^{*}$ & $0.21(344.5: 125.8,563.2)^{*}$ & $0.26(553.7: 288.5,819.0)^{*}$ & 0.10 (4905: -1669,11479) & 0.09 (5166: -2273,12606) \\
\hline Swing time (s) & $0.22(143.0: 82.4,203.6)^{*}$ & 0.19 (134.4: 69.7,199.2)* & $0.13(338.4: 94.7,582.1)^{*}$ & $0.20(607.3: 333.7,880.9)^{*}$ & 0.12 (8579: 1317,15840) & 0.14 (11048: 3465,18630)* \\
\hline $\begin{array}{l}\text { Stance time } \\
\text { asymmetry }\end{array}$ & $0.01(0.3:-2.0,2.6)$ & $-0.04(-1.5:-4.6,1.5)$ & $0.00(0.1:-9.0,9.3)$ & $-0.05(-8.6:-21.5,4.4)$ & $0.03(86.1:-182.2,354.3)$ & $-0.04(-186.6:-541.8,168.7)$ \\
\hline $\begin{array}{l}\text { Swing time } \\
\text { asymmetry }\end{array}$ & $-0.07(-1.3:-2.7,0.1)$ & $-0.06(-1.3:-3.1,0.5)$ & $-0.06(-4.4:-10.0,1.2)$ & $-0.07(-6.6:-14.2,1.0)$ & $-0.03(-50.4:-217.3,116.6)$ & $-0.06(-150.2:-359.6,59.2)$ \\
\hline $\begin{array}{l}\text { Step length } \\
\text { asymmetry }\end{array}$ & $-0.06(-1.1:-2.6,0.4)$ & $-0.07(-1.4:-3.0,0.2)$ & $-0.01(-0.9:-7.0,5.3)$ & $-0.08(-7.0:-13.8,-0.1)$ & $-0.02(-46.3:-230.0,137.5)$ & $-0.06(-135.9:-326.4,54.6)$ \\
\hline
\end{tabular}

Fast walking speed condition

\begin{tabular}{|c|c|c|c|c|c|c|}
\hline $\begin{array}{l}\text { Fast speed } \\
(\mathrm{cm} / \mathrm{s})\end{array}$ & $0.31(0.24: 0.18,0.30)^{*}$ & $0.14(0.18: 0.07,0.20) *$ & $0.27(0.84: 0.61,1.07)^{*}$ & $0.21(0.72 ; 0.45,0.98)^{*}$ & $0.31(27.4: 20.5,34.2)^{*}$ & $0.21(18.9: 11.3,26.5)^{*}$ \\
\hline $\begin{array}{l}\text { Cadence } \\
\text { (steps/min) }\end{array}$ & $-0.22(-0.36:-0.53,-0.19)^{*}$ & $-0.17(-0.29:-0.48,-0.10)^{*}$ & $-0.16(-1.01:-1.70,-0.32)^{*}$ & $-0.24(-1.72:-2.51,-0.92)^{*}$ & $-0.06(-10.7:-31.9,10.5)$ & $-0.09(-18.3:-40.5,3.8)$ \\
\hline
\end{tabular}




\section{$0.11(130.2 \text { : } 43.4,217.0)^{*} \quad 0.18$ (192.9: 107.9,277.9)*}

\section{$0.20(0.5: 0.2,0.8)^{*}$}

0.21 (107.7: 51.4,164.0)*

0.16 (83.4: 24.8,142.1)*

0.14 (289.9: 63.0,516.8) 0.15 (105.8: 41.5,170.1)* 0.17 (129.7: 67.9,191.5)* $-0.09(-0.6:-1.3,0.1)$ $-0.04(-1.3:-4.4,1.9)$

DS\% (\%)

Stance time asymmetry

Swing time asymmetry Step length asymmetry

Bold and $*$ denotes significant at $p \leq 0.01$.
$0.19(1.9: 0.7,3.1)^{*}$

$0.27(2.8: 1.6,4.0)^{*}$ 0.23 (522.5: 275.6,769.5)*

0.10 (283.3: 33.2,533.5) 0.18 (565.8: 294.2,837.3)* $-0.01(-0.2:-2.6,2.2)$

$-0.09(-11.3:-20.9,-1.8)$

$-0.08(-6.4:-12.5,-0.4)$

0.01 (0.7: $-5.4,6.8)$
$-0.07(-10.5:-21.9,1.0)$

$-0.07(-7.0:-14.6,0.6)$

$-0.10(-8.7:-15.9,-1.5)$

\section{$0.04(1415:-1248,4078)$}

$0.08(22.2:-15.2,59.6)$

0.03 (2014: -4988,9017)

0.06 (5303: -2328,12934)

-0.12 (-76.4: -147.9,-4.9)

0.07 (2059: $-340,4458)$

$0.11(31.3:-3.3,65.9)$ 0.08 (4864: -2049,11777) 0.11 (9179: 1648,16710)

-0.15 (-119.5: -205.3,-33.7)*

- $0.11(-387.6:-667.2,-107.9)^{*} \quad-0.02(-60.9:-387.5,265.8)$

$-0.08(-187.9:-365.3,-10.6) \quad-0.04(-104.4:-312.2,103.3)$

$-0.03(-74.8:-261.6,112.0) \quad-0.08(-186.5:-385.5,12.6)$

CPM = counts per minute from Actigraph. 
Table 3. Longitudinal analysis investigating the ability of the gait variables to predict change in physical activity levels. All analyses were adjusted for age, gait speed at baseline (preferred or fast as appropriate), and the baseline value for activity outcomes.

\begin{tabular}{|c|c|c|c|c|c|c|}
\hline & \multicolumn{2}{|c|}{$\begin{array}{l}\text { Annualised change in minutes of high intensity } \\
\text { activity per day }\end{array}$} & \multicolumn{2}{|c|}{ Annualised change in average CPM } & \multicolumn{2}{|c|}{ Annualised change in steps/day } \\
\hline & Women & Men & Women & Men & Women & Men \\
\hline \multicolumn{7}{|c|}{ Preferred walking speed condition } \\
\hline $\begin{array}{l}\text { Preferred speed } \\
(\mathrm{cm} / \mathrm{s})\end{array}$ & $0.17(0.16: 0.08,0.24)^{*}$ & $0.15(0.14: 0.06,0.23)^{*}$ & $0.17(0.53: 0.26,0.79) *$ & $0.18(0.63: 0.33,0.92)^{*}$ & $0.15(13.6: 5.2,22.0)^{*}$ & $0.21(19.3: 10.8,27.8) *$ \\
\hline $\begin{array}{l}\text { Cadence } \\
\text { (steps/min) }\end{array}$ & $-0.17(-0.11:-0.42,0.07)$ & $-0.01(-0.03:-0.32,0.26)$ & -0.17 (-0.99: $-1.87,-0.12)$ & 0.01 (0.06: -1.09,1.21) & $-0.03(-4.2:-31.8,23.3)$ & 0.00 (0.0: $-32.8,32.8)$ \\
\hline Step length (cm) & $0.08(0.2:-0.2,0.6)$ & $0.01(0.0:-0.4,0.4)$ & $0.16(1.5: 0.0,3.0)$ & $-0.01(-0.1:-1.8,1.5)$ & $0.01(1.8:-44.8,48.5)$ & $0.01(2.4:-44.8,49.7)$ \\
\hline Step time (s) & 0.12 (40.7: $-9.8,91.1)$ & $0.00(1.7:-51.8,55.3)$ & 0.17 (215.6: 35.9,395.3) & $-0.02(-27.8:-240.4,184.8)$ & 0.03 (1217: $-4501,6936)$ & 0.00 (-19: $-6107,6069)$ \\
\hline DS\% (\%) & $-0.13(-0.7:-1.3,-0.1)$ & $0.00(0.0:-0.6,0.6)$ & $-0.17(-3.3:-5.5,-1.1)^{*}$ & $-0.01(-0.1:-2.5,2.2)$ & $-0.23(-131.5:-201.4,-61.7)^{*}$ & $-0.03(-20.4:-89.4,48.6)$ \\
\hline \multicolumn{7}{|c|}{ Fast walking speed condition } \\
\hline $\begin{array}{l}\text { Cadence } \\
\text { (steps/min) }\end{array}$ & $-0.07(-0.09:-0.25,0.07)$ & $0.04(0.05:-0.10,0.21)$ & $-0.11(-0.53:-1.10,0.03)$ & 0.05 (0.28: $-0.33,0.89)$ & $-0.05(-6.3:-24.9,12.3)$ & $0.07(9.2:-8.2,26.6)$ \\
\hline Step length (cm) & $0.06(0.13:-0.15,0.42)$ & $-0.02(-0.04:-0.28,0.20)$ & $0.11(0.86:-0.15,1.86)$ & $-0.03(-0.25:-1.20,0.70)$ & 0.03 (6.8: -26.1,39.6) & $-0.04(-8.6:-35.9,18.8)$ \\
\hline Step time (s) & $0.08(35.2:-17.5,87.9)$ & $-0.03(-10.4:-59.5,38.6)$ & 0.12 (193.6: 5.0,382.2) & $-0.04(-73.4:-268.9,122.1)$ & 0.07 (3305: -2969,9578) & $-0.05(-2006:-7653,3641)$ \\
\hline DS\% (\%) & $-0.08(-0.4:-0.9,0.2)$ & $0.00(0.0:-0.6,0.6)$ & $-0.12(-2.1:-4.2,-0.1)$ & $-0.00(0.0:-2.4,2.4)$ & $-0.23(-118.4:-185.3,-51.5)^{*}$ & $-0.05(-29.3:-99.2,40.6)$ \\
\hline
\end{tabular}

Bold and * denotes significant at $p \leq 0.01 . \beta=$ standardised regression coefficient, $B=$ unstandardised regression coefficient, DS\% $=$ double support percentage of gait cycle,

CPM = counts per minute from Actigraph. 


\begin{tabular}{|c|c|}
\hline $\begin{array}{l}\text { Identification: } 6966 \text { (Population of } \\
\text { people born between } 1936 \text { and } 1942 \\
\text { with address in Trondheim, Norway) }\end{array}$ & $\begin{array}{l}\text { Did not respond: } 3721 \\
\text { Declined to participate: } 1424 \\
\text { Excluded at screening: } 70 \\
\text { Declined to participate after screening: } 184\end{array}$ \\
\hline $\begin{array}{l}\text { Assessed at baseline and randomised: } \\
1567\end{array}$ & \multirow{2}{*}{$\begin{array}{l}\text { Missing data: } 344 \\
\text { Missing due to - } \\
\text { - Not given an Actigraph at baseline assessment, } \\
\text { declined to wear device or Actigraph data did no } \\
\text { meet validity criteria: } 294 \\
\text { - Missing or invalid gait data: } 50\end{array}$} \\
\hline$\downarrow$ & \\
\hline $\begin{array}{l}\text { Analysed in cross-sectional study: } 1223 \\
\text { (18\% of population) } \\
1198 \text { had preferred speed variability } \\
\text { outcomes } \\
864 \text { had fast sped variability outcomes }\end{array}$ & $\begin{array}{l}\text { Gait data: } \\
\text { Only one trial available at preferred gait speed } \\
\text { for } 3 \text { participants } \\
\text { Only one trial available at fast gait speed for } 6 \\
\text { participants }\end{array}$ \\
\hline & \multirow{4}{*}{$\begin{array}{l}\text { Missing data: } 390 \\
\text { Missing due to - } \\
\text { - Not given Actigraph, declined to wear device or } \\
\text { Actigraph data did not meet validity criteria at } \\
\text { follow-up: } 390\end{array}$} \\
\hline$\downarrow$ & \\
\hline $\begin{array}{l}\text { Analysed in longitudinal study: } 833 \\
\text { (12\% of population) } \\
815 \text { had preferred gait speed variability }\end{array}$ & \\
\hline $\begin{array}{l}\text { outcomes } \\
576 \text { had fast gait speed variability } \\
\text { outcomes }\end{array}$ & \\
\hline
\end{tabular}

